\title{
PARA UMA CONCEPÇÃO EPISTEMOLÓGICA DA INCERTEZA
}

\section{FOR AN EPISTEMOLOGICAL CONCEPTION OF UNCERTAINTY}

\author{
Celso Luiz Ludwig \\ Universidade Federal do Paraná - UFPR - (Curitiba, Paraná, Brasil) \\ Recebimento: 18 out. 2018 \\ Aceitação: 10 abr. 2019
}

\begin{abstract}
Como citar este artigo / How to cite this article (informe a data atual de acesso / inform the current date of access):
LUDWIG, Celso Luiz. Para uma concepção epistemológica da incerteza. Revista da Faculdade de Direito UFPR, Curitiba, PR, Brasil, v. 64, n. 1, p. 97-117, jan./abr. 2019. ISSN 2236-7284. Disponível em: $<$ https://revistas.ufpr.br/direito/article/view/62405>. Acesso $\quad$ em: 30 abr. $2019 . \quad$ DOI:
\end{abstract} http://dx.doi.org/10.5380/rfdufpr.v64i1.62405.

\section{RESUMO}

O objetivo deste texto é o de apresentar alguns poucos aspectos que impactam a mudança epistemológica em torno do conceito de certeza e incerteza. $\mathrm{O}$ enfoque tem como diretriz central a passagem da ciência tradicional para a nova ciência paradigmática. A ideia central consiste em mostrar o fundo epistemológico da transição da certeza para incerteza como determinação principal desse tema em tempos atuais e suas implicações nos campos práticos, em particular no mundo jurídico. O conhecimento tradicional de importantes momentos da filosofia, seja no contexto da ontologia, seja na tradição moderna da teoria do conhecimento é referência inevitável, bem como a caracterização da ciência tradicional e da nova ciência. Assim, os conceitos oriundos de outros campos do saber, em especial da nova física e da nova biologia, a destacar a auto-organização, a instabilidade e a complexidade, foram decisivos para uma nova ideia orientadora de uma concepção epistemológica da incerteza. Por fim, a conclusão foi a de ressaltar não a aplicação da nova teoria epistemológica ao conceito de certeza e incerteza, mas a sua implicação neste tema. Implicação que atinge os diversos saberes, tangenciando inclusive tal implicação o campo jurídico, a partir da ideia de indeterminação epistemológica.

\section{PALAVRAS-CHAVE}

Teoria. Certeza e incerteza. Ciência tradicional e nova ciência. Incerteza e direito.

\begin{abstract}
The objective of this paper is to present a few aspects that impact the epistemological change around the concept of certainty and uncertainty. The central focus is the transition from traditional science to the new paradigmatic science. The central idea is to show the epistemological background of the transition from certainty to uncertainty as the main determination of this theme in present times and its implications in the practical fields, particularly in the legal world. The traditional knowledge of important moments of philosophy whether in the context of ontology or in the modern tradition of knowledge theory is an inevitable reference, as well as the characterization of traditional science and the new science. Thus, concepts from other fields of knowledge, especially the new physics and new biology, highlighting self-organization, instability and complexity, were decisive for a new guiding idea of an epistemological conception of uncertainty. Finally, the conclusion was to emphasize not the application of the new epistemological theory to the concept of certainty and uncertainty, but its
\end{abstract}


implication in this theme. Implication that affects the several fields of knowledge, including the legal field, from the idea of epistemological indeterminacy.

\section{KEYWORDS}

Theory. Certainty and uncertainty. Traditional science and new science. Uncertainty and law.

\section{INTRODUÇÃO}

São muitas as maneiras de procurar, rastrear, encontrar, dimensionar e avaliar o que se caracteriza como incerteza e insegurança no direito e do direito. No sentido tradicional - e somente nele -, creio que existe a possibilidade de proceder análises no interior do sistema jurídico - ponto de vista interno -, e também análises do exterior do sistema jurídico - ponto de vista externo. E em cada um deles não deixam de existir pontos de partida e de chegada os mais diversos e multifacetados. De algum modo, pode-se até pensar a questão na ideia de sistema no direito (e até que ponto o tema da incerteza/insegurança não ganha aí sua dramaticidade), ou pode-se pensar o direito no sistema (e aí a dramaticidade assume talvez outros contornos, outras descrições possíveis, e até mesmo outras avaliações sobre a questão da incerteza e insegurança).

Meu ponto de partida será externo, e nele apenas tangencio as questões que transitam da ontologia à epistemologia ${ }^{1}$. Na reflexão a ótica tem em conta o horizonte da totalidade, como categoria de categorias. Para ser fundamento, a totalidade necessita ter ao menos certo nível de existência. Totalidade não como algo que tem sentido, mas que é fundamento do sentido - algo que dá sentido, ou faz ter sentido, ou faz ter outro sentido. Enfim, produz sentido.

Portanto, na medida do possível, a problemática questão da incerteza será considerada sob o ponto de vista da totalidade epistemológica especialmente. Ao mesmo tempo, importa assinalar que este enfoque aponta um dos seus aspectos, que embora de relevância decisiva, não afasta outras possibilidades a serem enfrentadas em posterior reflexão. Para exemplificar, pode-se mencionar a questão da possibilidade do estudo da incerteza no campo da ontologia geral, na teoria geral dos

\footnotetext{
${ }^{1} \mathrm{O}$ presente artigo resulta de pesquisa em fase inicial sobre o recorrente tema da segurança/insegurança jurídica. O tema volta a ter importância na discussão jurídica tendo em vista o momento conjuntural de tensão política, jurídica e institucional, especialmente vivida no Brasil dos recentes anos. Em particular, o tema da insegurança jurídica voltou a ser assunto recorrente e preocupante, tanto sob o ponto de vista da teoria do direito, quanto dos efeitos políticos. A reflexão sobre o tema comporta abordagens diversas. A escolha do recorte epistemológico está no ponto de partida, e nele originariamente a categoria da incerteza. Não há pretensão de originalidade quanto à categoria da certeza/incerteza epistemológica. Pretende-se a inversão epistemológica do movimento ao acentuar a incerteza como referência principal, para adiante poder pensar o sentido da questão no campo do direito. Não se trata, portanto, de uma reflexão sobre o princípio dogmático da certeza do direito ou da segurança jurídica, mas de algo (condição) pressuposto para o debate. Imagino que o tema comporta, talvez até exija, também a passagem da epistemologia à hermenêutica bem como o caminho da epistemologia à retórica e argumentação, tarefa no entanto para além dos limites deste texto inicial, que ainda terá que ir adiante no próprio campo da epistemologia jurídica.
} 
sistemas, sejam eles sociais, vivos ou cibernéticos. Ou então, estreitando o objeto de estudos, pensar o sentido da incerteza e da insegurança tanto na compreensão tópica, sistemática e sistêmica do direito.

Outros enfoques também são possíveis e talvez necessários. Isso porque a certeza e a incerteza têm uma longa história na filosofia ocidental - estabelecendo-se assim um marco histórico e conceitual - seja sob o ponto de vista ontológico (ser e pensar visto como idênticos, sem brechas para a incerteza, seja na ordem do ser, seja na ordem do pensar), ou do ponto de vista gnosiológico (afinal, de um lado aposta-se na certeza, e de outro, nas mais variadas formas de ceticismo - desde o sistemático ao metódico, apontam-se motivos suficientes para afirmar a dúvida como suspensão de possibilidade da certeza), ou, ainda, na ótica axiológica, em que geralmente o relativismo assume a fisionomia mais conhecida.

Há, portanto, múltiplas racionalidades e mesmo irracionalidades no caminho histórico e conceitual do termo e de sua condição de categoria filosófica. Seu sentido muitas vezes depende diretamente do contexto histórico e social no qual se encontra e a maneira como é utilizado. Mas também depende do sistema, subsistema, campo ou esfera da vida em que aparece. Mesmo considerando o direito - a certeza do direito, ou a certeza no direito -, as implicações referem-se a diferentes aspectos. A certeza ou incerteza (insegurança) podem estar relacionadas às pessoas na condição de usuários do direito (do ordenamento jurídico). Ou então, o tema pode estar referido ao próprio sistema jurídico em relação a si mesmo (por exemplo, quanto aos elementos da unidade e da ordem das partes entre si e das partes com o todo), ou ainda, a certeza ou a incerteza que decorre da relação de um sistema em relação ao outro ou ao seu entorno, e particularmente no caso da relação do sistema direito com os demais sistemas, e também com seu ambiente.

A longa história da certeza e da incerteza transforma o próprio sentido dos termos, e assume na sociedade moderna caraterísticas típicas de passagem, como apontado a seguir, de uma certa (certeza) estabilidade para a instabilidade, de uma estrutura ou funcionamento da simplicidade para a complexidade, e da subjetividade para a intersubjetividade. Esse movimento a partir dos elementos apontados revela um deslocamento que reclama da reflexão novas orientações no campo da ontologia, da gnosiologia, da axiologia, da hermenêutica, da epistemologia, e assim por diante. Essa exigência também ocorre no campo do direito. Neste texto pretende-se uma aproximação epistemológica da incerteza, com a finalidade de balizar eventual e necessário sentido da certeza. 


\section{DA ONTOLOGIA À EPISTEMOLOGIA}

1. Ontologia e epistemologia como totalidades. A primeira e grande mudança que ocorre pode ser vista na passagem da ontologia à epistemologia. Se houve época em que a afirmação de que o ser se diz de vários modos fundava uma maneira de se referir à realidade mais atual e presente (Aristóteles), ela teria sido suplantada pelo tempo no qual o conhecer se diz de modo certo ou como certeza (DESCARTES, 2010). Há nessa perspectiva um largo caminho que vai da verdade do ser à verdade do conhecer (internamente, também da opinião [da dóxa] à verdade [da episteme], em ambos os casos). Ainda que sob alguma ótica vivemos tempos de manifesto e declarado niilismo, o tema faz sempre ressurgir a premissa epistemológica, ainda que implícita, de que alguma verdade poderia ser pressuposta ou possível, mesmo que sempre provisória e inconclusa. Isso parece bastante complexo em tempos de acentuada incerteza nos mais diversos sentidos que o termo pode assumir ou indicar.

A ontologia aqui referida tem o sentido aristotélico visto em sua totalidade como filosofia do ser. Desde logo tal concepção indica a prevalência da questão ontológica sobre as demais dimensões, como por exemplo a possibilidade gnosiológica, lógica, ética, retórica, política, de análise da realidade. Mesmo assim, a prudência recomenda que a ontologia seja compreendida no contexto de sua Metafísica (ARISTÓTELES, 2012) como um todo. E nesta perspectiva da totalidade, múltiplos são os sentidos e conceitos necessários para definição, que embora distintos entre si, são complementares (REALE, 2014, p. 37-51).

Numa primeira definição a metafísica consiste na ciência das causas e dos princípios primeiros e supremos das coisas. O filósofo se refere à causa e ao princípio, ou seja, ao porquê ou à razão de ser da coisa, aquilo pelo qual a coisa é o que é; enfim, condições ou fundamentos das coisas. Mas, provavelmente não se compreende o sentido da ontologia somente com tal definição. Pois, a metafísica também é definida como ciência do ser enquanto ser e do que compete ao ser enquanto ser. Ou seja, é ontologia.

O difícil significado histórico da definição expressa a ideia da totalidade da realidade e do ser, em contraste às partes ou aspectos do ser, que por derradeiro implica o estudo das causas $e$ princípios supremos de todos os seres (como de resto adiantado na primeira definição).

No entanto, numa terceira definição a metafísica aparece como teoria da substância (ov $\sigma \curlywedge \alpha$ ), sendo que este é o sentido mais importante, e o fundamento de todos os outros (incluído aí um quarto sentido de metafísica que a define como ciência teológica). Para reforçar, portanto, a definição da metafisica como ciência das causas e dos princípios do ser, configura-se como ciência 
das causas e dos princípios da substância. Este é o sentido de ontologia aqui indicado para o movimento na expressão “da ontologia à epistemologia”.

Na busca da certeza do ser, Aristóteles continua seu caminho da definição, neste momento, explicando que o ser se diz de vários modos, isto é, ora como ser acidental, ora ser por si, ora como verdade, e por fim, o ser como potência e como ato. Uma ontologia assim concebida (em largas e insuficientes notas), é sabido, foi profundamente atacada na modernidade filosófica, especialmente pela filosofia kantiana, ao postular o fim da metafísica concebida ontologicamente, dada a impossibilidade do conhecimento das coisas em si mesmas, tendo em vista as condições da estrutura a priori do sujeito de conhecimento (KANT, 2012).

Uma nova teoria do conhecimento é elaborada - uma revolução copernicana do conhecimento, como é conhecida - tendo o sujeito como ponto de partida, e não mais o ser. Trata-se do caminho que permite o movimento da ontologia na direção da gnosiologia, e posteriormente desembocando na epistemologia. Essa preocupação com o conhecimento, com os processos mentais ou com a atividade de representação, tendo em vista as condições que tornam possível o conhecimento, é desde o século XVII investigada por filósofos.

Como bem menciona Richard Rorty (1994, p. 20), devemos especialmente a Locke a noção de uma teoria do conhecimento com base na compreensão dos processos mentais que permitem o conhecimento; a Descartes a noção de mente como uma entidade separada do corpo e na qual ocorrem processos na atividade do conhecer; e no século XVIII, especialmente a Kant (2012), a noção de filosofia como um tribunal da razão pura e toda sua concepção de sujeito transcendental com uma especial estrutura a priori da razão nas formas da sensibilidade (espaço e tempo), dos conceitos e categorias do entendimento (quantidade, qualidade, causalidade, finalidade...), e da razão propriamente dita como capaz de organizar um sistema de conhecimento, reduzindo toda a multiplicidade nas ideias de alma, cosmos e Deus.

No século XIX, a ideia da filosofia como disciplina fundacional que assegura asserções de conhecimento foi consolidada pelos neokantianos. É nessa linha de pensamento que o conhecer foi definido como representação: representar acuradamente o que ocorre fora da mente (RORTY, 1994, p. 27). Compreender a possibilidade ou não do conhecimento estudando a natureza e os processos da mente no ato de conhecer. Pode-se confiar (ter certeza) na mente? As representações produzidas na mente ou pela mente correspondem ao que está fora dela? Portanto, a preocupação principal da filosofia foi a de elaborar uma teoria geral da representação, desafio que foi enfrentado num período caracterizado pelo sucesso da ciência natural. 
Os limites do conhecimento assim concebido, em especial no contexto das ciências modernas que desembocam numa episteme positivista, gerando em certas tendências o cientificismo ou para muitos o cientismo, concebida como a ideologia das ciências, parecem claros hoje. Por tal razão a crítica epistemológica se inicia neste ponto. Alguns, apenas alguns, elementos dessa transformação serão indicados no próximo passo, começando com a própria crítica epistemológica.

2. Da crítica epistemológica. Em larga medida vivemos um tempo que se define, e isso inclui muitos e abalizados pensadores, como época marcada pelas desconstruções, na concepção capitaneada por Derrida. Necessárias desconstruções, diga-se, pelo menos em certo sentido e em certa medida.

Talvez o melhor começo das desconstruções tenha seu ponto de partida na própria epistemologia. Mais precisamente, refiro-me à chamada epistemologia interna das ciências, que, ao proceder a uma análise crítica dos procedimentos cognitivos que objetivam assegurar os fundamentos de cada uma das ciências, removeu muitas certezas já dogmatizadas. Em seu procedimento desconstruiu certezas tidas como bem alicerçadas. Também faço referência à epistemologia derivada, que cumpriu e cumpre papel irrenunciável na produção do conhecimento, na medida em que observa como o conhecimento de um determinado campo ou ciência é produzido e o que o torna possível; em suma, quando indaga sobre a participação do sujeito (do pesquisador) na produção e definição do conhecimento, e a função do objeto, neste particular modo de conhecer que é o científico. Papel decisivo porque mostra certas condições de possibilidade do conhecimento, que em geral estão para além da experiência do existente mais imediato.

De igual modo, atenta para a consciência que é preciso ter em relação aos obstáculos epistêmicos que devem ser passo a passo superados, e da necessária vigilância crítica constante para que a produção científica possa anunciar o novo. A epistemologia crítica cumpre nesse passo importante papel. No entanto, a questão não se encerra aí.

3. A epistemologia da ciência tradicional e o pressuposto da simplicidade. O aspecto a ser sublinhado diz respeito à concepção de ciência que explícita ou implicitamente produz, fundamenta e justifica as diferentes ideias de certeza e incerteza, em geral, e as certezas e incertezas que compõem 
ou atravessam os diversos campos, sejam eles teóricos ou práticos. No caso do enfoque epistemológico pode-se elucidar a questão tomando a ciência como referência.

De modo geral, no campo das certezas científicas - que permitiram a concepção que se convencionou chamar epistemologia positivista, ou episteme positivista - o paradigma da própria concepção de ciência utilizado foi o da chamada ciência tradicional, por toda a evidência.

Porque esta, tanto na versão empirista - que tem na experiência o critério determinante da cientificidade, seja como condição necessária da produção e criação de conceitos e hipótese, enfim, condição de surgimento da teoria científica, seja como elemento indispensável de confirmação -, como na versão racionalista - que tem na razão a fonte de onde nascem as hipóteses das teorias científicas -, afirma a possibilidade do conhecimento científico como resultado de uma radiografia do real, imagem da realidade como ela objetivamente é. O conhecimento científico desta maneira proclama sua capacidade de conter a representação da realidade. Em apertada síntese, pode-se dizer que essa premissa que afirma a ciência como sendo conhecimento objetivo da realidade opera a partir de três conceitos básicos: a simplicidade, a estabilidade e a objetividade (VASCONCELLOS, 2003, p. 67 et seq.).

O pressuposto da simplicidade do objeto remete à ideia de que o pesquisado é em geral simples, ou então se tornará simples quando separado em partes, em elementos simples, portanto, marcado pela atitude metodológica da análise e das relações lineares de causa e efeito.

O pressuposto da estabilidade resulta da concepção de que o mundo é estável - ainda que a aparência mais fenomênica sugira o contrário -, e também o objeto específico da pesquisa é visto como estável, o que permite seu controle e a consequente previsibilidade.

E, por fim, o pressuposto da objetividade vê o pesquisador como independente e separado da realidade pesquisada, e esse é o critério da cientificidade, a permitir um conhecimento do mundo como ele é.

Assim, no conjunto e a partir dos pressupostos anunciados se engendra a conhecida epistemologia positivista, inicialmente metodologia produzida nas chamadas ciências da natureza, metodologia, enfim, das ciências exatas, para a posterior recepção no mundo das ciências humanas, históricas, sociais, hermenêuticas e jurídicas. Mundos, aquele e este, com a convicção da certeza.

A crença científica consistia em boa parte em proceder de tal forma que fosse possível ultrapassar o mundo - ou o objeto como microcosmos - em sua aparência de complexidade, para encontrar a simplicidade. A tarefa é essa mesma: encontrar o simples no complexo, ordem subjacente ao caos aparente. E ao identificar a unidade, partir dela para descrever e explicar os fenômenos, produzir conceitos, axiomas, e identificar suas leis. Estabelecidas as relações causais lineares, o 
critério da cientificidade estaria presente, e também a verdade científica possível e necessária. Não se trata de uma verdade qualquer, mas de uma verdade certa, ou com a possibilidade da certeza. Mas além de saber explicar, a ciência tornou-se também capaz de fazer previsões em torno dos fenômenos.

Presente o fator causal, pode-se prever a consequência e, se for o caso, exercer controle sobre o fenômeno. O pressuposto dessa possibilidade exige uma concepção de mundo no qual prevalece a ordem, ou seja, a estabilidade da realidade ou do objeto da pesquisa. Um mundo ordenado em que a repetição, a constância, a invariabilidade, enfim, o estável prevalece sobre o dinâmico, de modo que as relações de possíveis variáveis sejam altamente prováveis, a permitir a descrição por meio de conceitos, leis e princípios.

A crença científica também concebe a realidade como já existente, independente do observador, o que permite ao pesquisador um conhecimento que representa a realidade. Conhecimento é representação da realidade, do mundo, do objeto específico. O cientista descobre as leis dos fenômenos, daí a noção da descoberta científica. Nessa definição, a descoberta científica permite a elaboração de conceitos, axiomas, premissas e hipóteses, que no seu conjunto formam uma teoria. Teoria científica que em geral, mas nem sempre, é submetida à experimentação, tida como uma espécie de teste da teoria, seu critério de verificação. Nessas condições - ou a partir de tal premissa epistemológica - se acredita poder alcançar a objetividade do saber, ou seja, a verdade científica com a marca da objetividade exige a eliminação dos aspectos subjetivos, o que tem como consequência a obtenção da verdade certa, a verdade como certeza.

Essa maneira de pensar configura o que se costuma chamar de paradigma ${ }^{2}$ da ciência tradicional. Há nessa configuração uma ontologia: uma maneira de conceber o ser do universo, uma simplificação do universo, do mundo, da realidade, dos fenômenos (enfim, o pressuposto da simplicidade); há também uma gnosiologia: uma convicção cognitiva em torno da possibilidade de saber, de conhecer como tudo ou quase tudo funciona (o pressuposto da estabilidade); e há, por fim, uma epistemologia: a convicção de que se pode conhecer a realidade como ela efetivamente é (o pressuposto da objetividade).

O paradigma da ciência tradicional, com as diferentes dimensões mencionadas, e suas variadas manifestações, permite, entre outras possibilidades, reconhecer a configuração epistemológica de um paradigma científico positivista. Este paradigma pressupõe como efeito também a crença na neutralidade do sujeito, na transparência do objeto e na pureza da linguagem

\footnotetext{
${ }^{2}$ A noção de paradigma da ciência será usada no sentido próximo ao elaborado por Thomas Kuhn em sua obra A estrutura das revoluções científicas (1992), seja na concepção de matriz disciplinar, seja na concepção de exemplos compartilhados.
} 
na produção da ciência. Um dispositivo capaz de produzir verdades científicas, dada a ontologia, a gnosiologia e a epistemologia que, em resumo, tornam tais verdades possíveis, verdades que gozam de segurança (por sua permanência) e de certeza (por sua objetividade).

\section{DA CERTEZA À INCERTEZA}

\section{A epistemologia da nova ciência e o pressuposto da complexidade: da certeza à incerteza.} Segundo Vasconcelos (2003, p. 101), apesar da amplitude enorme nos desenvolvimentos contemporâneos da ciência, três são os eixos que indicam a transformação do paradigma da ciência tradicional, e que contrastam com os pressupostos desta: o pressuposto da complexidade (contrasta com o da simplicidade da ciência tradicional), o da instabilidade (em contraste com a estabilidade), e o da intersubjetividade (em contraste com a objetividade) ${ }^{3}$.

Na questão da complexidade há o reconhecimento de que o processo da simplificação não conduz à identidade de algo. Ao contrário, obscurece as inter-relações que existem entre todos os fenômenos do universo, e, portanto, é imprescindível lidar com a complexidade do mundo em todos os níveis. O pressuposto da complexidade consiste em reconhecer e em assumir a complexidade do mundo, complexidade que já existia, mas não era reconhecida como importante, e sim concebida apenas como aparente.

Num primeiro sentido, afirma-se que a complexidade existia, mas não era reconhecida. Portanto, a existência da complexidade neste caso não é nova, apenas passou a ser reconhecida. Em outro sentido, creio, podemos dizer que surgiu, ou houve um aumento de complexidade nos tempos atuais, em especial nos séculos XX e XXI. Assim, as teorias da complexidade se ocupam do tema, especialmente da segunda metade ao final do século XX. Nas últimas décadas do século XX, em especial na década de 1980 o tema tem uma explosão que atinge todas as ciências ${ }^{4}$. Nas palavras de Henri Atlan, cuja obra motivou o colóquio anunciado na última nota, a "complexidade [...] seria o objeto privilegiado das ciências no século XX, como a energia e a entropia o foram no século XIX” (ATLAN, 2003, p. 105).

\footnotetext{
${ }^{3}$ A reflexão não tem por objeto a ideia de sistema, ou eventualmente, a passagem de uma visão sistemática para uma visão sistêmica. Assim, as categorias serão examinadas na lógica da passagem do paradigma da ciência tradicional para a nova ciência, na perspectiva epistemológica.

${ }^{4}$ Maria José Estes de Vasconcelos (2003, p. 104) nos diz que "Esse tema da complexidade explodiu de tal maneira dentro das ciências que, em junho de 1984, aconteceu em Cérisy, na França, um colóquio, cujos anais têm 463 páginas, que se intitulou 'As Teorias da Complexidade' (Soulié et al. 1984). Reuniu especialistas das mais diversas áreas: matemática, matemática aplicada, informática, física, engenharia, biofísica, biologia, medicina, imunologia, física estatística, bioinformática, inteligência artificial, robótica, simulação de sistemas adaptativos, psicologia, psiquiatria, psicanálise, psicossomática, sociologia, ciências cognitivas, filosofia das ciências, epistemologia”.
} 
Ilya Prigogine (2011, p. 11) mostra que no decorrer das últimas décadas uma nova racionalidade científica foi elaborada. O desenvolvimento extraordinário da física, com os conceitos de “não equilíbrio e da dinâmica dos sistemas dinâmicos instáveis associados à ideia de caos”, exigiu a reformulação de conceitos, a começar pela noção de tempo formulada desde Galileu ${ }^{5}$. O autor reconhece que nas últimas décadas do século XX uma nova ciência surgiu: a física dos processos de não equilíbrio, gerando novos conceitos, como a auto-organização e estruturas dissipativas "que são hoje amplamente utilizadas em áreas que vão da cosmologia até a ecologia e as ciências sociais, passando pela química e pela biologia” (PRIGOGINE, 2011, p. 11).

A revisão do conceito de tempo na física (flecha do tempo) ocorreu a partir dos sistemas dinâmicos instáveis. Se o paradigma da ciência tradicional privilegiava a ordem, a estabilidade e a própria objetividade, agora em qualquer nível de observação reconhece-se a importância central das flutuações e da instabilidade. Para o autor, "Noções como a de caos tornaram-se populares e invadem todos os campos da ciência, da cosmologia à economia” (PRIGOGINE, 2011, p. 12).

A incorporação da instabilidade propiciou uma nova significação das leis da natureza. Essa transformação ademais ocorre pela física quântica, que, com a recepção da instabilidade, leva a uma quebra da simetria do tempo. Como efeito "tanto na dinâmica clássica quanto na física quântica, as leis fundamentais exprimem agora possibilidades e não mais certezas” (PRIGOGINE, 2011, p. 13).

Parece importante aqui sublinhar como o conceito de instabilidade na ciência física abala o campo da certeza, deslocando-a para a dimensão da possibilidade, com o que se abre caminho para a delimitação, aos poucos, da incerteza. Ainda para acentuar o sentido do que foi exposto anteriormente sobre o paradigma da ciência tradicional, e assim evidenciar o contraste, a palavra de Ilya Prigogine elucida a transformação apontada: "assistimos ao surgimento de uma ciência que não mais se limita a situações simplificadas, mas nos põe diante da complexidade do mundo real [...]” (PRIGOGINE, 2011, p. 15).

Portanto, foi pela nova ciência da física que o mundo simples, estável, regular e ordenado, sucumbiu ao mundo processo, muito mais do que um mundo estado. Uma física do devir, característica marcante da instabilidade. Assim, embora o físico e químico Ilya Prigogine tenha desenvolvido suas teorias nessas áreas, conforme seus próprios testemunhos, sua preocupação se estendia para o restante da vida, e da vida para a natureza (CAPRA, 1996, p. 80-82).

Pode-se dizer, ainda, que, nesse contexto da nova epistemologia paradigmática, o conceito da auto-organização permite a compreensão complementar dos próprios conceitos de instabilidade e

\footnotetext{
${ }^{5} \mathrm{O}$ autor investiga o tema da flecha do tempo em sua obra $\mathbf{O}$ fim das certezas: tempo, caos e as leis da natureza. Tradução Roberto Leal Ferreira. 2. ed. São Paulo: Editora Unesp, 2011.
} 
complexidade. Pois, o fenômeno da auto-organização foi pesquisado em sistemas diferentes, por pesquisadores de vários países, como informa Capra (1996, p. 79) - (Ilya Prigogine na Bélgica, Hermann Haken e Manfred Eigen na Alemanha, James Lovelock na Inglaterra, Lynn Margulis nos Estados Unidos, Humberto Maturana e Francisco Varela no Chile, para citar alguns). Concluiu-se que os diferentes modelos de sistemas auto-organizadores compartilham certas características-chave.

Na cibernética ${ }^{6}$ se observa a primeira diferença entre a concepção inicial de autoorganização e os sistemas posteriores, diferença que consiste na criação de novas estruturas e novos modos de comportamento no decorrer do processo de auto-organização. Outro aspecto comum desses modelos de auto-organização ocorre nos sistemas abertos que operam apartados do equilíbrio. E o terceiro traço comum aos modelos é o da interconexão não linear dos componentes do sistema, o que permitiu ao autor concluir:

Resumindo essas três características dos sistemas auto-organizadores, podemos dizer que a auto-organização é a energia espontânea de novas estruturas e de novas formas de comportamento em sistemas abertos, afastados do equilíbrio, caracterizados por laços de realimentação internos e descritos matematicamente por meio de equações não-lineares. (CAPRA, 1996, p. 80).

Edgar Morin é certamente o autor mais conhecido em nossa área de saber, por tratar o tema e formular a filosofia de um pensamento complexo. Ele também participou do evento antes mencionado (cf. VASCONCELOS, 2003, p. 104), e no ano anterior (1983) foi um dos mais importantes participantes de um debate em Lisboa sobre $O$ problema epistemológico da complexidade, e posteriormente, em 1990, publicou Introdução ao pensamento complexo, livro inteiramente dedicado ao tema, além de outras publicações de grande repercussão.

O autor dedicou ampla pesquisa ao tema da complexidade do mundo moderno, insistindo, em várias obras, na ideia de um pensamento complexo (MORIN, 2005). Para o interesse do tema da incerteza, impende destacar que para ele a complexidade não se opõe ao conceito de simplicidade, mas significa transdisciplinaridade, única forma de se compreender e explicar o mundo que nos cerca. Considera que as vantagens de outrora da analítica cartesiana e do positivismo se transformaram atualmente em obstáculos para a compreensão da realidade. O método cartesiano, de dividir cada dificuldade em tantas partes quanto possível e necessário e procedendo do mais simples e mais fácil para alcançar paulatinamente o mais difícil e complexo (DESCARTE, 2010, p. 18-19), deve ser substituído, para compreender os fenômenos em toda sua complexidade - certamente influência das

\footnotetext{
${ }^{6}$ O modelo da cibernética não será incluído neste texto, embora seja fonte de nova racionalidade e de conceitos inovadores, como é caso da auto-organização, para a formulação de uma nova epistemologia, em especial para a concepção de incerteza.
} 
ideias e conceitos oriundos da cibernética wieneriana e da nova ciência física (com seus conceitos de auto-organização e instabilidade).

A breve referência aos autores acima tem por finalidade apenas indicar como, de campos de saber bem distintos, a complexidade torna-se um pressuposto epistemológico transdisciplinar. Reconhece-se que a complexidade não é apenas, como se acreditava inicialmente, característica específica de certos fenômenos, como os biológicos e sociais (assim como já ocorrera com a instabilidade), mas os ultrapassa alcançando os mais diversos campos, sistemas e subsistemas. Os estudos de Edgar Morin ressaltam que a complexidade se torna mais evidente, ou pelo menos se mostra mais intensa, diante de dificuldades empíricas e de dificuldades lógicas próprias dos tempos atuais.

No contexto dessas e outras referências, Vasconcelos (2003, p. 107) distingue na complexidade três aspectos, que nos interessam no desdobramento da reflexão, no caminho da concepção de uma ciência novo-paradigmática: (1) o problema lógico que remete ao pressuposto da complexidade; (2) o problema da desordem que remete ao pressuposto da instabilidade; e (3) o problema da incerteza que remete ao pressuposto da intersubjetividade. Não se trata aqui de expor os argumentos de cada uma dessas dimensões, trazidas inicialmente pela física. Apenas pontuo o cerne dessa questão, e o problema epistemológico que encerra. Desde a física se apontou o problema lógico, na medida em que a lógica clássica se mostrou insuficiente para lidar com contradições ${ }^{7}$.

Ante duas concepções opostas, tradicionalmente se esperava dos físicos uma posição sobre qual das duas seria aceita. Entretanto, isso deixou de ser assim a partir da concepção (Niels Bohr) de que proposições contraditórias são de fato complementares, e de que logicamente se deveriam associar termos que se excluem mutuamente (VASCONCELOS, 2003, p. 107). Essa nova postura pressupõe transdisciplinaridade e ao mesmo tempo torna-se transdisciplinar. Exige uma forma de pensamento complexo que assuma ou permita abordar as contradições, e não as excluir. O princípio da complementaridade (Bohr) permitiu ao cientista desafiar a lógica, ao salientar a dualidade posição/momentum já apontada por Heisenberg quando da formulação do princípio da incerteza. Também foi a física a trazer o problema da desordem ou a tendência para a desordem, ao reconhecer (Boltzmann) que o calor corresponde à agitação desordenada das moléculas, por exemplo.

A nova concepção derrubou o dogma central da física, de um mundo identificado pela ordem, estável, funcionando como uma máquina mecânica perfeita. A nova visão, ao reconhecer a

\footnotetext{
${ }^{7}$ Menciona-se o caso do início do século XX, no campo da microfísica, quando se defrontaram duas concepções da luz, ora definida como ondas, ora como partículas (2003, p. 107).
} 
desordem, exigiu inclusive um novo pensamento, para incluir a indeterminação e a imprevisibilidade dos fenômenos.

O terceiro aspecto, e que aqui nos interessa sobremodo, é o problema da incerteza. A problemática relação entre sujeito e objeto no campo gnosiológico e epistemológico é bastante conhecida na filosofia. No entanto, com a formulação do princípio da incerteza por Heisenberg, o tema da complexidade dessa relação ganha formalmente espaço no âmbito da ciência ${ }^{8}$. Mesmo nas ciências físicas impera o princípio da incerteza.

O tema da objetividade do conhecimento incomoda o mundo da filosofia há muito tempo, sabemos todos. Dos filósofos modernos, Kant formula a teoria da revolução copernicana do conhecimento que pode ser tomada aqui como referência desse problema. A guinada do objeto para o sujeito transcendental abala os alicerces da teoria da verdade como correspondência, mas não aniquila inteiramente a possibilidade do conhecimento a partir do novo critério de sua validação. No entanto, deve-se reconhecer de qualquer modo que se trata de uma solução conhecida como solipsismo, na medida em que o sujeito é a referência necessária e autossuficiente. Enfim, sua epistemologia, por mais profunda e sofisticada que seja, é um bom exemplar do que hoje se chama de filosofia típica do paradigma da consciência, ou paradigma do sujeito.

O giro linguístico da filosofia consagra, desde Wittgenstein, Apel (2000) e Habermas (1990, p. 18-19), uma mudança paradigmática que significaria não apenas o trânsito da objetividade para a subjetividade, mas a configuração de uma nova totalidade de sentido, com fundamento na intersubjetividade linguística. Enfim, o denominado paradigma da linguagem ou da intersubjetividade. A intersubjetividade é agora o critério de validação do conhecimento (LUDWIG, 2006, p. 22-27).

Parece prudente enfatizar, no entanto, que essa mudança ocorre igualmente no campo da filosofia; ou melhor, nesse caso, provém da filosofia, desde que se leve em conta a mudança paradigmática ocorrida na própria história da filosofia. Não é uma mudança provocada pela ciência, ainda que os filósofos tenham utilizado como material para a reflexão filosófica estudos da antropologia e da linguística. A mudança começa a ocorrer no campo das ciências quando o questionamento da objetividade surge em seu interior, especialmente na física. A ideia cartesiana de

\footnotetext{
${ }^{8}$ Para minimamente ilustrar a questão transcrevo as palavras de Vasconcelos (2003, p. 108) ao mencionar o referido princípio da incerteza: não se pode ter, simultaneamente, valores bem determinados para a posição e para a velocidade, em mecânica quântica. Mostrou assim que nem mesmo a mensuração podia produzir certeza e que, "ao se lançar luz sobre um elétron, a fim de poder 'vê-lo’, isso inevitavelmente o colocava fora do curso, afetando sua velocidade ou sua posição” (Strathern 1998, 9. 74). Ou seja, o cientista se torna uma intervenção perturbadora sobre aquilo que quer conhecer. Isso também vem requerer uma nova forma de pensar, que reintegre o observador na sua observação, não só nas ciências humanas, mas também nas ciências físicas.
} 
saber e de racionalidade predominava também nessa área. Heisenberg desencadeou a passagem da crença na objetividade para a intersubjetividade, ao mostrar que o ato de observação interferia e alterava o objeto, o que impossibilita conhecê-lo tal como é na realidade. Com o princípio da incerteza Heisenberg remete à impossibilidade de obter-se um conhecimento objetivo também no mundo físico, e que, portanto, a questão do observador não se limita às ciências humanas. É claro que aqui ainda não se alcança o postulado que funda o chamado paradigma da linguagem no campo da filosofia, mas abre-se também para às ciências o problema da comunicação. Ocorre uma transformação da filosofia (APEL, 2000).

Inicialmente, surge a concepção de um pensamento dialógico que seria o entrecruzamento das diferentes perspectivas possíveis a partir das múltiplas visões de realidade. Como se percebe, a questão ainda não alcança os postulados do paradigma da linguagem, ou o conceito de princípio dialógico de Morin. Mais ainda, neste caso, as diferentes visões resultam da existência de múltiplos observadores, os quais têm focos em distintos aspectos dos fenômenos, talvez algo mais próximo das dificuldades do observador empírico, concreto, pós-modernamente considerado.

Tanto Edgar Morin quanto Humberto Maturana e Francisco Varela problematizam o tema e apontam reflexões que se ocupam do observador. Ou, mais do que isso, produzem conceitos ou até mesmo teorias do observador.

Destaco aqui em especial os biólogos chilenos Maturana e Varela (2001). A teoria desses autores é um convite à suspensão do hábito de cair na tentação da certeza. Suspensão necessária porque o fenômeno do conhecimento e as ações que dele surgem, ou seja, toda a experiência cognitiva, inclui de um modo pessoal aquele que conhece, desde a raiz de sua estrutura biológica. Formulam uma teoria biológica do conhecer. Este enraizamento da estrutura biológica, inultrapassável, é o motivo pelo qual toda a experiência de certeza é um fenômeno individual cego em relação ao ato cognitivo do outro. É assim uma experiência de solidão que só é transcendida no mundo que um cria junto com o outro (MATURANA; VARELA, 2001, p. 22).

Os aforismos-chave da teoria merecem ser citados: todo fazer é um conhecer e todo conhecer é um fazer; e tudo o que é dito é dito por alguém. Acentuam, assim, a circularidade entre ação cognitiva e experiência. E como a linguagem é nossa maneira particular de ser humanos e estar no fazer humano, ela é ponto de partida, instrumento cognitivo e também problema (MATURANA; VARELA, 2001, p. 32). Então, o ponto de partida é a consciência de que todo conhecer é um fazer daquele que conhece, ou seja, depende da estrutura de quem conhece (MATURANA; VARELA, 2001, p. 40). 
O conhecer é o fazer que está enraizado na maneira de seu ser vivo, em sua organização. As bases biológicas do conhecer remetem à totalidade do ser vivo que conhece (MATURANA; VARELA, 2001, p. 40). A organização diz respeito às relações que têm de existir, ou têm de ocorrer entre os componentes de algo, para que algo seja (MATURANA; VARELA, 2001, p. 50-54), e assim possa ser reconhecido como membro de uma classe específica de coisas ${ }^{9}$, ou de seres vivos. E quando falamos destes, supomos algo comum entre eles, caso contrário não usaríamos o termo seres vivos. A classe dos seres vivos se define assim pela sua organização autopoiética (MATURANA; VARELA, 2001, p. 52). E entende-se por estrutura de algo os componentes e relações que constituem concretamente uma unidade particular e configuram sua organização (MATURANA; VARELA, p. 54). Em síntese, é a organização autopoiética que caracteriza o ser vivo; e os seres vivos se distinguem porque têm estruturas distintas, mas são iguais em organização.

Preocupado com a questão do conhecimento, a investigação de Humberto Maturana procurou responder às seguintes indagações: O que ocorre no fenômeno da percepção?, e O que é a vida? Na resposta articulou as duas questões, ao conceber que a cognição e o viver são um único e mesmo fenômeno: conhecer é viver e viver é conhecer. O próprio autor apresentou o que denominou de leis sistêmicas: (1) quando as relações entre o ser vivo e seu ambiente começam a se conservar, essas relações começam a se modificar para se conservarem; (2) o passado não é necessário e determinante para causar o que ocorre, só ocorre o que a estrutura atual do sistema lhe permite; e (3) tudo ocorre segundo a coerência estrutural do momento e os seres vivos vão se movendo na conservação do viver (MATURANA, 2001).

Como bem observa Vasconcelos (2003, p. 249), as três leis indicadas por Maturana remetem aos seus fundamentais conceitos de organização autopoiética (a organização é uma autoorganização), de fechamento estrutural (é impossível determinar, de fora, o que o sistema fará) e acoplamento estrutural (nas interações entre sistema vivo e ambiente, ambos mudam, o organismo sua estrutura - e o ambiente). Assim, a validação das experiências subjetivas - do observador, por exemplo - sempre é feita nos espaços consensuais, nos quais todo o conhecimento é produzido, seja da ciência ou outro saber qualquer, no inevitável pressuposto da intersubjetividade. Portanto, esse espaço não é o da verdade como correspondência, nem como representação, mas um espaço de consenso - da verdade como consenso -, de acoplamento estrutural entre observadores. Portanto, seja

\footnotetext{
${ }^{9} \mathrm{O}$ exemplo dos autores neste caso é um objeto como a cadeira: é necessário reconhecer certas relações que acontecem entre as partes que chamo de pés, espaldar, assento, de tal maneira que é possível sentar nela; que seja feita de madeira e pregos, ou de plástico e parafusos, é irrelevante; essa situação é universal, no sentido que a fazemos constantemente como ato cognitivo básico, e que consiste em gerar classes de qualquer tipo.
} 
pela via da filosofia, seja pela via da ciência (biológica), afirma-se a intersubjetividade como mudança paradigmática.

Assim, em sua totalidade a nova concepção de ciência - a ciência novo-paradigmática ultrapassa o campo da ciência no sentido estrito e alcança a condição de uma nova teoria do conhecimento, ou especialmente, uma nova epistemologia. A nova concepção de ciência tem no pensamento complexo a síntese da nova epistemologia.

Essa nova epistemologia tem diversas implicações. Uma primeira implicação - não se trata de mera e simples transposição mecânica de um campo para outro, nem mesmo de aplicação, que é outra coisa - que pode ser considerada como premissa na produção do conhecimento em cada uma das áreas, sistemas ou campos, não importa se este ou aquele, desde a nova concepção que levou a conhecer o conhecer. E por exemplo, (1) tomar a nova epistemologia em conta como pensador, como pesquisador, e (2) assumir em cada campo (como, por exemplo, no campo jurídico) a complexidade que lhe é própria, e no interior dos subsistemas reconhecer a complexidade dos temas específicos. A nova epistemologia teria, assim, as suas primeiras implicações, a partir das ações cognitivas pautadas pela complexidade, instabilidade e intersubjetividade, nova totalidade, fundamento que dá sentido ao princípio da incerteza.

E nessa trilha, a nova ciência paradigmática atende em boa medida às exigências da nova ciência, que numa concepção geral pode ser identificada como ciência construtivista. A tese central dessa concepção construtivista identifica a atuação do pesquisador científico como alguém que formula conceitos, axiomas, postulados e definições, enfim, hipóteses que têm sua origem na razão concepção racionalista -, mas que deve testá-las na experiência, e se for o caso retificá-las - exigência própria da concepção empirista - e, ao mesmo tempo, e ainda, considerar os resultados sempre provisórios, falsificáveis e corrigíveis. Isso porque o conhecimento científico está condicionado às limitações humanas da razão, fonte das hipóteses, e limitado às condições sempre parciais da experimentação, pois esta é sempre uma experiência limitada e não é toda a experiência possível da realidade. Para exemplificar, cabe dizer que o objeto é uma construção lógico-mental e experimental feita nos limites da pesquisa de campo ou em laboratório. Portanto, a noção de ciência construtivista, concepção típica dos avanços epistemológicos dos séculos XX e XXI, exige considerar o objeto da pesquisa a partir de novos pressupostos: a complexidade, a instabilidade e intersubjetividade, com as implicações epistemológicas envolvidas, em especial no que concerne ao tema da incerteza, agora em nova concepção. 
5. Do moderno ao pós-moderno: do sólido ao líquido. Não só Edgar Morin e Humberto Maturana, mas também Niklas Luhmann (1980) e Zygmunt Bauman, ambos sempre em grande evidência, com a autopoiese naquele, e a liquidez neste, tratam da nova racionalidade dos novos tempos, antes mencionada.

Limito-me a algumas observações sobre Bauman (2007). A metáfora autoexplicativa da liquidez dos tempos atuais - nesse sentido, pós-modernos - revela bem o que caracteriza a nossa época como totalidade. Uma sociedade líquida em sua relação com a sociedade moderna concebida como sólida. Em tese estamos diante da inevitável analogia com a questão epistêmica da verdade: a verdade líquida contrasta com a verdade sólida. Em Bauman (2008) - assim também em Luhmann - a liquidez é uma característica, ou mais do que isso, um conceito referido a vários, senão a todos os setores da vida. Para nosso autor o indivíduo consumidor, típico da sociedade pós-moderna, vive num estado perene de incertezas, como mostra em seus inúmeros escritos, entre os quais mencionamos Tempos Líquidos (2007), em contraste com o homem moderno que encontrava certeza no mundo sólido da produção. A liquidez gera nas pessoas um permanente - a única estabilidade - temor de exclusão, de perda e de rejeição. Nesse mundo líquido o medo se estende também às dimensões existenciais e afetivas. Os laços afetivos se tornam instáveis e atingem na crítica do autor a condição de amor líquido.

Segundo o autor, algumas mudanças de curso seminais e intimamente interconectadas, em boa parte do planeta, criaram um novo ambiente, sem precedentes na vida individual. Para justificar seu argumento, Bauman (2007, p. 7-10) indica a anteriormente indicada (1) passagem da época sólida para a líquida, condição na qual as organizações sociais (estruturas que orientam e limitam as ações e escolhas dos indivíduos) não podem manter suas formas por muito tempo, decompondo-se e dissolvendo-se rapidamente; além desse aspecto, acrescenta o fato da (2) separação entre poder e política, que, unidos no Estado moderno (Estado-nação), hoje se dispersam e se afastam na direção de um espaço global politicamente descontrolado, sendo que as demandas e problemas locais são terceirizados, gerando uma incontrolável incerteza, na medida em que são abandonadas pelo Estado, e entregues à lógica do mercado; e extrai, dessa nova situação, a retração ou redução gradual da segurança comunal, o encolhimento dos laços comunitários e de solidariedade, o que, além de fragilizá-los, faz com que passem a ser reconhecidamente temporários; e por efeito, a sociedade passa a ser vista cada vez mais como uma rede, em vez de uma estrutura; registra (4) o colapso do pensamento, do planejamento e da ação em longo prazo, o próprio desaparecimento das estruturas que alicerçavam tais possibilidades; a vida passou a ser vida fragmentada, com orientações mais laterais do que verticais; e, por fim, (5) aponta que a responsabilidade em relação aos efeitos da nova 
época recaem sobre o indivíduo, de quem se exige a virtude da flexibilidade, ou seja, a prontidão para a mudança repentina de vida, de estilo de vida, abandono, sem arrependimentos, dos compromissos e lealdades, na busca de alternativas impostas mais pelas disponibilidades das circunstâncias do que pelas preferências. Esse conjunto de características mostra uma transformação, na sociedade, similar ao que se observa no campo epistemológico, isto é, a possibilidade de estender a categoria analítica da incerteza para campos além do epistemológico.

6. Da nova concepção epistêmica ao sistema direito. Bauman procura mostrar como as mudanças apontadas impactam a sociedade e a vida das pessoas em condições de incerteza endêmica. Para ele, a era das incertezas. Penso que esse poderia ser o ponto de partida para o aprofundamento do tema em pauta, o movimento que vai da certeza para a incerteza, ou até mesmo, da incerteza para a certeza.

Esse movimento permite, em particular, novas perguntas sobre o tema na esfera do direito. Ou, pelo menos, possibilita outro sentido para as já clássicas perguntas e questionamentos. Como foi antecipado no início, a presente reflexão não se ocupa da questão da certeza e da incerteza nos termos tradicionais dos estudos da dogmática jurídica ou da teoria do direito. Não está em jogo o debate sobre o sentido, limites e efeitos do princípio da certeza ou segurança jurídica. A centralidade da argumentação diz respeito ao debate sobre a condição de possibilidade de tal racionalidade e de tal princípio, e ao mesmo tempo, dá sentido às perguntas e às respostas sobre sua operabilidade.

Como pensar o tema na sociedade e no direito, que têm as determinações da complexidade, da contingência, da instabilidade e da intersubjetividade? Existe a possibilidade de descrever o tradicional tema da certeza do direito (ou segurança jurídica) sem a previsibilidade, sem a linearidade, sem a controlabilidade e a ordem? Qual o sentido de buscar no direito a certeza e a incerteza ante o anúncio epistemológico da reflexividade, da provisoriedade, da incontrolabilidade, da autorreferência, da organização autopoiética, do fechamento estrutural, da recursividade e demais marcas da nova ciência paradigmática? Afinal, que tipo de certeza pode ser esperada no e pelo direito? Que tipo de certeza o direito pode oferecer?

Portanto, esse conjunto final de perguntas é indicativo não somente da tensão entre certeza e incerteza que não se excluem por serem distintas, mas também aponta para a inevitável tensão entre paradigmas epistêmicos que se diferenciam. Para, por fim, sugerir as novas tensões e suas implicações no tema da certeza e da incerteza do direito oriundas da nova ciência paradigmática. A implicação da questão epistemológica do tema no direito se pretende presente em todo o texto de maneira implícita, e que se torna explícita no conjunto das perguntas agora formuladas. 


\section{CONCLUSÃO}

Com a concepção da passagem da ciência tradicional à nova ciência - ciência novoparadigmática - ou seja, de uma epistemologia positivista para uma epistemologia pós-positivista, seria possível nova concepção da certeza e da incerteza? A transposição é legítima? E, mesmo no também reduzido perfil baumaniano apresentado, podemos nos perguntar, com Mário Losano ${ }^{10}$, se uma tal visão sociológica se prestaria para uma formulação de uma teoria do direito líquido ${ }^{11}$.

Essa questão, a da passagem das ciências da natureza, ou mais propriamente, das complexas teorias físicas e biológicas para o mundo social, não é nova, e é enfrentada das mais diversas maneiras. Também é profícuo o debate entre modernidade e pós-modernidade nesse sentido. Não é, no entanto, essa a questão que está posta no presente texto. Não se trata propriamente de transposição, muito menos de transposição mecânica, de conceitos e premissas da física ou da biologia para a filosofia, ou para as ciências humanas, normativas, sociais, históricas, hermenêuticas ou jurídicas. Não se trata da - já nesse sentido velha - questão da recepção da episteme das ciências físico-naturais para os demais campos.

É de outra questão que se trata, como já vimos. Talvez a seguinte pergunta, como conclusão, possa elucidar o que está em jogo: Como a nova concepção de conhecimento, que leva em conta alguns elementos como complexidade, instabilidade, intersubjetividade, liquidez (nos termos do já exposto, ainda que limitadamente) permite conceber de maneira nova a incerteza e suas implicações na própria (1) produção do conhecimento; (2) quais suas implicações na produção do conhecimento num campo específico (como o direito); e por fim, (3) quais suas implicações outras, seja no campo da teoria ou da prática do direito? Creio que essa é uma questão de fundo - apenas tangenciada sobre a certeza e a incerteza, sua implicação no direito e, talvez, sua implicação na insegurança.

\footnotetext{
${ }^{10}$ Cf. LOSANO, G. Mario. Sistema e estrutura no direito. Tradução Carlos Alberto Dastoli. 3 v. São Paulo: Martins Fontes, 2011. O autor responde que provavelmente sim, pelo fato de que as últimas décadas revelam a fragilidade de todas as regras, inclusive as jurídicas. Cita como exemplo as normas do direito internacional, considerando-as as mais frágeis juridicamente, indicativo da liquidez em comento. De modo mais amplo, menciona a visão baumaniana, na categoria da liquidez do mundo como útil a orientar uma análise sociológica da aplicação do direito positivo, indicando inclusive sua progressiva fragilidade ou liquefação, na direção da linha do direito livre e do uso alternativo do direito.

${ }^{11}$ Cumpre apenas apontar que a observação da notar anterior é do autor, e assinalar que não é essa a minha perspectiva de análise no presente texto, porque não tenho em vista nem a eventual liquidez normativa do ordenamento jurídico diretamente, nem a análise da aplicação do direito, mas a concepção da certeza, ou melhor, da incerteza desde os argumentos apresentados, e as implicações daí decorrentes (inclusive no mundo jurídico).
} 


\section{REFERÊNCIAS}

APEL, Karl-Otto. Transformação da Filosofia. Tradução Paulo Astor Soethe. 2 v. São Paulo: Loyola, 2000.

ARISTÓTELES. Metafísica. 2. ed. Tradução Edson Bini. São Paulo: Edipro, 2012.

BAUMAN, Zygmunt. Medo líquido. Tradução Carlos Alberto Medeiros. Rio de Janeiro: Zahar, 2008.

BAUMAN, Zygmunt. Tempos líquidos. Tradução Carlos Alberto Medeiros. Rio de Janeiro: Zahar, 2007.

CAPRA, Fritjof. A teia da vida: uma nova compreensão científica dos sistemas vivos. Tradução Newton Roberval Eichemberg. São Paulo: Cultrix, 1996.

DESCARTE, René. Discurso sobre o método. Tradução Norberto de Paula Lima, Torrieri Guimarães. São Paulo: Folha de São Paulo, 2010.

HABERMAS, Jürgen. Pensamento Pós-metafísico. Tradução Flavio Beno Siebeneichler. Rio de Janeiro: Tempo Brasileiro, 1990.

KANT, Immanuel. Crítica da razão pura. Tradução Fernando Costa Mattos. Petrópolis: Vozes, 2012.

KUHN, Thomas S. A estrutura das revoluções científicas. 3. ed. São Paulo: Perspectiva, 1992.

LOSANO, G. Mario. Sistema e estrutura no direito. Tradução Carlos Alberto Dastoli. 3 v. São Paulo: Martins Fontes, 2011.

LUDWIG, Celso Luiz. Para uma filosofia jurídica da libertação: paradigmas da filosofia, filosofia da libertação e direito alternativo. Florianópolis: Conceito Editorial, 2006.

LUHMANN, Niklas. Legitimação pelo procedimento. Tradução Maria da Conceição Côrte-Real. Brasília: UnB, 1980.

MATURANA, Humberto; VARELA, Francisco. A árvore do conhecimento: as bases biológicas da compreensão humana. Tradução Humberto Mariotti e Lia Diskin. São Paulo: Palas Athena, 2001.

MORIN, Edgar. Introdução ao pensamento complexo. Tradução Eliane Lisboa. Porto Alegre: Sulina, 2005.

PRIGOGINE, Ilya. O fim das certezas: tempo, caos e as leis da natureza. Tradução Roberto Leal Ferreira. 2. ed. São Paulo: Editora Unesp, 2011.

REALE, Giovanni. Metafísica/Aristóteles: ensaio introdutório. Tradução Marcelo Perine. 3. ed. São Paulo: Edições Loyola, 2014. 
RORTY, Richard. A filosofia e o espelho da natureza. Tradução Antônio Trânsito. 3. ed. Rio de Janeiro: Relume Dumará, 1994.

VASCONCELOS, Maria José Esteves de. Pensamento sistêmico - o novo paradigma da ciência. Campinas: Papirus, 2003.

Celso Luiz Ludwig Formado em Filosofia, Letras e Direito. Mestre e Doutor pelo Programa de Pós-Graduação em Direito/UFPR. Professor de Filosofia do Direito na UFPR e na UNINTER. E-mail: celsoludwig@gmail.com 